\title{
Macroeconomic influences on optimal asset allocation
}

\author{
T.J. Flavin ${ }^{\mathrm{a}, *}$, M.R. Wickens ${ }^{\mathrm{b}}$ \\ ${ }^{a}$ Department of Economics, National University of Ireland, Maynooth, Co. Kildare, Ireland \\ ${ }^{\mathrm{b}}$ Department of Economics and Related Studies, University of York, York Y010 5DD, UK
}

Received 3 February 2001; received in revised form 15 June 2001; accepted 7 August 2002

\begin{abstract}
We develop a tactical asset allocation strategy that incorporates the effects of macroeconomic variables. The joint distribution of financial asset returns and the macroeconomic variables is modelled using a VAR with a multivariate GARCH (M-GARCH) error structure. As a result, the portfolio frontier is time varying and subject to contagion from the macroeconomic variable. Optimal asset allocation requires that this be taken into account. We illustrate how to do this using three risky UK assets and inflation as a macroeconomic factor. Taking account of inflation generates portfolio frontiers that lie closer to the origin and offers investors superior risk-return combinations.
\end{abstract}

(C) 2002 Elsevier Science Inc. All rights reserved.

JEL classification: G11

Keywords: Asset allocation; Macroeconomic effects; Multivariate GARCH

\section{Introduction}

This paper shows how macroeconomic information can be used to improve asset allocation. Evidence on the use of financial and macroeconomic variables to predict financial asset returns, which is a burgeoning literature, is not necessarily of most use for asset allocation. Indeed, we show that information about the volatility, not the level, of asset returns plays a more significant role in portfolio selection models. The idea of this paper is to exploit

\footnotetext{
* Corresponding author. Tel.: +353-1-708-3369; fax: +353-1-708-3934.

E-mail address: thomas.flavin@may.ie (T.J. Flavin).
} 
the time series structure of volatility contagion between financial and macroeconomic variables. If macroeconomic volatility can help predict the volatility of asset returns, then this can be used to improve tactical asset allocation. This is done by relating the mean variance portfolio frontier to the macroeconomic factors.

Traditional methods of portfolio selection such as the mean variance analysis of Markowitz (1952, 1959) and the CAPM due to Lintner (1965) and Sharpe (1964) are based on the assumption of constant asset return volatility and hence a constant portfolio frontier. It has been noted by, for example, Harvey (1991) that the covariance matrix of returns, from which the portfolio frontier is formed, is in fact time varying. Ferson and Harvey (1997) exploit this in their cross-sectional analysis of asset pricing. This implies that instead of the portfolio frontier being based on the unconditional covariance matrix of returns, which is constant, it should be calculated from the conditional covariance matrix, which is time varying.

This is the methodology used by Flavin and Wickens (1998) where it is shown that investors in UK assets could enjoy a significant reduction in portfolio risk by employing a time-varying conditional covariance matrix instead of a constant, unconditional covariance matrix to form the portfolio frontier. As the frontier is also time varying, the portfolio needs to be continuously rebalanced. Financial asset returns were conditioned on past realised values using a multivariate $\operatorname{GARCH}(1,1)-\mathrm{M}-\mathrm{GARCH}(1,1)$ - process to model the volatility contagion.

We extend this methodology to take account of macroeconomic variables. By modelling the asset returns jointly with the macroeconomic variables, we can assess and take account of the influence of the macroeconomic variables on both the conditional mean and the conditional covariance matrix of the asset returns. The resulting time-varying conditional covariance matrices are then used to develop a tactical asset allocation strategy in which individual asset holdings are continuously updated in response to changes in their perceived riskiness, which are due in part to macroeconomic effects. In this illustration, we consider only one macroeconomic variable, inflation. ${ }^{1}$

In order to help determine the additional benefits of taking account of macroeconomic effects, we build on the analysis of Flavin and Wickens (1998) who examine three UK risky assets: equity, a long government bond, and a short-term bond. We find that inflation exerts a strong influence on the volatility of these asset returns and on the shape and location of the portfolio mean variance frontier. As a result of taking account of inflation effects, we find that for portfolios for which the asset shares are restricted to be nonnegative, the optimal share of equities increases from $70 \%$ to $74 \%$, the share of the long bond's share falls from $20 \%$ to $14 \%$, and the share of the short bond increases from $10 \%$ to $12 \%$. These are significant changes.

The paper is structured as follows: Section 2 reviews the literature on the relation between macroeconomic variables and the returns and volatility of financial assets. Section 3 explains

\footnotetext{
1 The extension of portfolio analysis to take account of macroeconomic volatility contagion, even of one variable, is a nontrivial issue. For example, in a recent paper on variable selection for portfolio choice, Ait-Sahalia and Brandt (2001) confine their selection to just financial asset returns.
} 
how to take account of macroeconomic factors in asset allocation. Section 4 presents the econometric model of the joint distribution of returns and the macroeconomic variable. Our choice of the macroeconomic variable and a description of the data are given in Section 5. The estimates of the econometric model are reported in Section 6. Section 7 contains an analysis of the portfolio frontier and the optimal asset shares both ignoring and taking account of the influence of inflation. Our conclusions are reported in Section 8.

\section{Asset returns and macroeconomics}

There are good theoretical reasons to believe that macroeconomic variables affect asset returns. If returns are defined in nominal terms, and investors are concerned with real returns, then we would expect that nominal returns would fully reflect inflation in the long term, though how much of this is transmitted in the short term is still unclear. As a result, stocks should prove to be an effective hedge against inflation ex post. Changes in inflation expectations are also thought to be a major factor in determining the shape of the yield curve. General equilibrium models of asset price determination relate nominal asset returns to consumption, as well as inflation.

Since the mid-1980s, there has been a growing literature on empirical evidence of the information contained in macroeconomic variables about asset prices. Most of this research is, however, about predicting financial asset returns, and very little is about forecasting asset price volatility. We briefly review some of this literature and then turn to the evidence on the macroeconomic influences on asset price volatility.

\subsection{Asset returns}

In this review, we focus mainly on evidence about the usefulness of macroeconomic variables in predicting stock returns. Similar factors seem also to affect bond markets. Fama and French (1989) provide evidence that forecasts of excess bond and stock returns are correlated, while Campbell and Ammer (1993) find that variables which are useful in forecasting excess stock returns can also predict excess bond returns.

Chen, Roll, and Rose (1986) are credited with being the pioneers in the asset return predictability literature following their paper identifying factors that can be potentially used to predict U.S. stock market prices. They found that the following are all significantly priced in the U.S. stock market: the spread between long- and short-term interest rates (a measure of the term structure or slope of the yield curve), expected and unexpected inflation, industrial production, and the spread between high- and low-grade bonds. Jankus (1997) shows that expected inflation is also a useful predictor of future bond yields.

In a similar vein, many papers provide evidence of the explanatory power of the dividend yield over annual U.S. stock returns (Campbell \& Shiller, 1988; Hodrick, 1992; Patelis, 1997; Rozeff, 1984, etc.). A positive correlation between the term structure of interest rates and stock price movements has been documented for the United States (Campbell, 1987; Keim \& Stambaugh, 1986; Patelis, 1997), while the slope of the term structure is found to have 
forecasting power for excess bond returns in, for example, Campbell and Shiller (1991), Fama (1984), and Tzavalis and Wickens (1997). Using cross-sectional data, Fama and French $(1992,1995)$ find support for a negative relation between price/book ratio and U.S. stock returns. Pesaran and Timmermann (1995) identify many factors that can influence returns on U.S. equities. These include the earnings-price ratio, the rates of return on 1- and 12-month Treasury bills, the change in domestic inflation, the change in industrial production, and monetary growth.

A parallel literature has emerged in the UK. Clare, Thomas, and Wickens (1993) show that the gilt-to-equity yield ratio (GEYR) contains predictive power over UK stock price movements. Clare and Thomas (1994) find that the current account balance, U.S. equity, German equity, the 90-day UK Treasury bill rate, the differential between the 90-day UK and U.S. Treasury bill rates; the irredeemable government bond index, the corporate bond index, the term structure of interest rates, and the dollar-to-pound exchange rate are all significantly priced in the UK stock market. Clare, Smith, and Thomas (1997) focus on the ability of lagged own values and lagged values of returns on other markets to predict UK stock returns.

Asprem (1989) conducted a wide-ranging analysis of the relation between stock market indices, portfolios of assets, and macroeconomic phenomena in 10 European countries. Interestingly, he finds that the linkages between stock prices and macroeconomic variables are most pronounced in Germany, the Netherlands, Switzerland, and the UK. For these countries, he finds strong evidence of a negative relation between stock prices and current and lagged values of the interest rate. Furthermore, current values of the U.S. term structure of interest rates are found to have significant explanatory power over stock returns in these countries. Consistent with other studies, he finds that asset prices and inflation are negatively correlated. This relation appears to hold both for past as well as expected future changes in inflation.

Since money supply growth and inflation are positively linked through the quantity theory of money, we would expect a similar relation between money growth and stock prices. Using the monetary base, $M 0$, as a measure of money supply, Asprem's evidence indicates a negative correlation. Only for the UK is this relation statistically significant. He finds that many other variables are not significantly related to stock prices, including measures of real economic activity, (trade-weighted) exchange rates and, with the exception of the UK, consumption.

\subsection{Asset return volatility}

In contrast to this wealth of evidence on the predictability of the level of asset returns, little attention has been paid in the literature to the ability of macroeconomic variables to influence asset price volatility.

Historically, financial market turbulence has been greatest in times of recession (see Schwert, 1989) and recent evidence suggests that stock market volatility is related to the general well-being of the economy. Clarke and De Silva (1998) report that "state-dependent variation in asset returns has strong implications for identifying an optimal asset allocation strategy," while Klemkosky and Bharati (1995) show that short-term predictability can be used to build profitable asset allocation models. 
In a test of the international CAPM, Engel and Rodrigues (1989) allow macroeconomic variables to influence the variance process of an ARCH model. They find that the square of the unanticipated monthly growth rate of dollar oil prices and the monthly growth rate of U.S. M1 are significant explanatory variables of the variance of residuals. Clare, O'Brien, Thomas, and Wickens (1998) demonstrate that when a number of macroeconomic variables are subjected to simultaneous shocks, they can have a significant influence on the conditional covariance matrix of excess returns. Wickens and Smith (2001) examine the macroeconomic influences on the sterling-dollar exchange rate that arise from general equilibrium and other models.

In summary, there is strong evidence that a broad range of macroeconomic factors are significantly priced in global stock markets. Changes in inflation (both realised and expected), interest rates, imports, consumption tend to be negatively correlated with stock returns, and bond yields tend to be positively related with stock returns. In contrast, to these findings for returns, much less attention has been paid to the influence of macroeconomic variables on the variances and covariances of returns. As this is crucial for optimal asset allocation, this is what we focus on.

\section{Optimal asset allocation}

Standard portfolio theory based on mean variance analysis or CAPM assumes a constant covariance matrix of asset returns. In principle, it is straightforward to extend this to a timevarying, or conditional, covariance matrix of returns (see, for example, Cumby, Figlewski, \& Hasbrouck, 1994; Flavin \& Wickens, 1998). As a result, the mean variance portfolio frontier also becomes time varying and optimal asset allocation requires a continuous rebalancing of portfolio shares.

The asset shares can be unrestricted, or constrained to be nonnegative to avoid short sales that may be prohibited for legal reasons. This is a situation facing a large number of fund managers, for example, UK pension funds. To aid comparisons between unconstrained and constrained asset allocations, the target rate of return when asset shares are constrained can be taken to be the average return on the unconstrained optimal portfolio.

To take account of the effect of macroeconomic variables on asset allocation, a further extension is required. This is achieved by augmenting the vector of excess returns with the macroeconomic variables, after suitably transforming them to stationarity where necessary. The joint distribution of this augmented vector, allowing for time-varying conditional heteroskedasticity in all variables is then required. The conditional covariance matrix of excess returns of this joint distribution is formed from the resulting multivariate marginal conditional distribution of the excess returns. The conditional distribution of excess returns will depend on the volatility of the macroeconomic variables, which can be used to help predict the covariance matrix of the excess returns and hence the portfolio frontier. The construction of the optimal portfolio is now obtained as before, but the asset shares will differ from those computed without taking account of the contagion effects from the macroeconomic variables. 


\section{Econometric issues}

\subsection{Model}

The joint distribution of the financial and macroeconomic variables is specified through an econometric model. We employ an $\mathrm{M}-\mathrm{GARCH}(1,1)$ model of excess returns. This has a timevarying covariance matrix.

GARCH models are widely used in financial econometrics. For asset allocation, it is necessary to use M-GARCH as the joint distribution of returns is required. Unfortunately, it is often difficult to estimate M-GARCH models due to dimensionality problems arising from the vast number of potential parameters to be estimated simultaneously. For example, for the most general formulation of the M-GARCH(1,1) model, termed the vec representation by Baba, Engle, Kraft, and Kroner (1990) - or BEKK - the number of parameters to be estimated increases at the rate of $n^{4}$, where $n$ is the number of variables. Thus, although in principle, for portfolio analysis, one would like a model capable of handling a large number of assets simultaneously, and with a structure flexible enough to capture the dynamic and leptokurtic characteristics of the distribution of asset returns, in practice, this choice is severely limited by numerical problems. We overcome this shortcoming by adopting the parameterisation of Flavin and Wickens (1998). ${ }^{2}$ This formulation is better suited to portfolio analysis in that it allows a considerable degree of flexibility in the conditional covariance matrix of returns yet is economical in the number of parameters it uses.

A general formulation of the $\mathrm{M}-\operatorname{GARCH}(p, q)$ model with constant mean can be written

$$
\begin{aligned}
& \boldsymbol{r}_{t}=\boldsymbol{\nu}+\boldsymbol{\zeta}_{t} \\
& \boldsymbol{\xi}_{t} \mid \Psi_{t} \sim N\left(0, \Omega_{t}\right) \\
& \operatorname{vech}\left(\Omega_{t}\right)=\boldsymbol{\Lambda}+\sum_{i=1}^{p} \boldsymbol{\Phi}_{i} \operatorname{vech}\left(\Omega_{t-i}\right)+\sum_{j=1}^{q} \boldsymbol{\Theta}_{j} \operatorname{vech}\left(\boldsymbol{\zeta}_{t-j} \boldsymbol{\zeta}_{t-j}^{\prime}\right)
\end{aligned}
$$

where $\boldsymbol{r}_{t}$ is an $n \times 1$ vector of excess returns over the risk-free rate, $E_{t} \boldsymbol{\xi}_{t} \boldsymbol{\xi}_{t}^{\prime}=\Omega_{t}$ is the timevarying conditional covariance matrix of excess returns, and vech(.) is the vector halfoperator that stacks the lower triangle of a square matrix into a column vector. Since $\Omega_{t}$ is symmetric, $\operatorname{vech}\left(\Omega_{t}\right)$ contains all the unique elements of the matrix. $\boldsymbol{\nu}$ is a vector of ones and $\boldsymbol{\zeta}_{t}$ is an $n \times 1$ vector of zero mean iid errors.

The parameter matrices $\Lambda, \Phi$, and $\Theta$ are all unrestricted. $\Phi$ and $\Theta$ are both square matrices of size $n(n+1) / 2, \boldsymbol{\Lambda}$ is a size $n(n+1) / 2$ vector, and $n$ is the number of assets in the problem. While there are just $n$ parameters in the mean vector, there are $n(n+1) / 2+(p+q) n^{2}(n+1)^{2} / 4$ parameters in the covariance matrix, implying that the number of parameters increases at a

\footnotetext{
2 This parameterisation is consistent with the covariance stationary model developed in Engle and Kroner (1995).
} 
rate of $n^{4}$. Even when $n=4$ and $p=q=1$, the conditional second moments require the simultaneous estimation of 210 parameters. This makes Eq. (1) an infeasible specification for asset allocation, especially if we would like to introduce additional assets.

Flavin and Wickens (1998) use a variant of the BEKK model that also ensures that the resulting time-varying covariance matrices symmetric and positive definite. ${ }^{3}$ The $\Phi$ and $\Theta$ matrices in Eq. (1) are diagonalised and the $\boldsymbol{i j}$-th element of the covariance matrix is influenced by its own lagged value and past values of $\boldsymbol{\xi}_{i} \boldsymbol{\xi}_{j}$ only. As in Flavin and Wickens (1998), we also specify the time-varying covariance matrix in error correction form. This has the advantage of separating the long-run from the short-run dynamic structure of the covariance matrix.

Augmenting the vector of asset returns with a vector of macroeconomic variables gives

$$
\begin{aligned}
& \mathrm{z}_{t}=\boldsymbol{\alpha}+\boldsymbol{\beta} z_{t-1}+\boldsymbol{\gamma d u m} 87+\boldsymbol{\zeta}_{t} \\
& \boldsymbol{\zeta}_{t} \mid \Psi_{t-1} \sim N\left(0, \mathbf{H}_{t}\right) \\
& \mathbf{H}_{t}=\mathbf{V}^{\prime} \mathbf{V}+\mathbf{A}^{\prime}\left(\mathbf{H}_{t-1}-\mathbf{V}^{\prime} \mathbf{V}\right) \mathbf{A}+\mathbf{B}^{\prime}\left(\boldsymbol{\zeta}_{t-1} \boldsymbol{\zeta}_{t-1}^{\prime}-\mathbf{V}^{\prime} \mathbf{V}\right) \mathbf{B}
\end{aligned}
$$

where $\mathbf{z}=(\mathbf{r}, \mathbf{m})^{\prime}$. In this study, $\mathbf{r}=(\text { ukeq, lbd, sbd })^{\prime}$, ukeq, lbd, and sbd represent the excess returns on UK equity, long government bonds, and short government bonds, respectively, and $\boldsymbol{m}$ is a single macroeconomic factor, the change in domestic inflation. Thus, inflation is constrained to have no effect on excess returns in the long run. More generally, both $\mathbf{r}$ and $\mathbf{m}$ will be vectors. dum87 is a dummy variable for the October 1987 stock market crash and is included only in the equity equation of the model.

The first term on the right-hand side of Eq. (3) is the long-run, or unconditional, covariance matrix. The other two terms capture the short-run deviation from the long run. By formulating the conditional variance-covariance structure in this way, we can decide more easily if the short-run dynamics have a useful additional contribution to make, and if the increased generality a parameter offers is worth the additional computational burden.

The speed with which volatility in the macroeconomic variables affect the volatility of excess returns is an important issue. This is governed, in part, by the choice of the $\mathbf{A}$ and $\mathbf{B}$ matrices. For example, if $\mathbf{A}$ and $\mathbf{B}$ are defined as lower triangular matrices then, partitioning conformably with $\mathbf{z}=(\mathbf{r}, \mathbf{m})$ implies that

$$
\mathbf{H}_{11, t}=V_{11}^{2}+A_{11}^{2} \mathbf{H}_{11, t-1}+B_{11}^{2} \varepsilon_{1, t-1}^{2}
$$

and

$$
\varepsilon_{1, t-1}=r_{t-1}-c_{1}-\beta r_{t-2}-\delta m_{t-2}
$$

\footnotetext{
${ }^{3}$ For a discussion of this and a review of alternative specifications, see Bollerslev, Engle, and Nelson (1994) and Bera and Higgins (1993).
} 
Thus, the volatility of excess returns is unaffected by the volatility of the macroeconomic variable.

Alternatively, if $\mathbf{A}$ and $\mathbf{B}$ are defined as full symmetric matrices then

$$
\begin{aligned}
\mathbf{H}_{11, t}= & V_{11}^{2}+\left(A_{11}^{2} \mathbf{H}_{11, t-1}+2 A_{11} A_{12} \mathbf{H}_{12, t-1}+A_{12}^{2} \mathbf{H}_{22, t-1}\right) \\
& +\left(B_{11}^{2} \varepsilon_{1, t-1}^{2}+2 B_{11} B_{12} \varepsilon_{1, t-1} \varepsilon_{2, t-1}+B_{12}^{2} \varepsilon_{2, t-1}^{2}\right)
\end{aligned}
$$

In Eq. (6), volatility in the macroeconomic variable is transmitted to the volatilities of the excess returns, but with a one period lag. This second formulation is therefore clearly preferable and it is what we use. $\mathbf{V}$ is specified, without loss of generality, as a lower triangular matrix.

In general, asset returns and macroeconomic variables could have both a time-varying conditional mean and covariance matrix. The evidence, however, is that excess equity and bond returns over the risk-free rate are almost serially independent and hence are difficult to predict. Moreover, inflation will have less effect on excess than straight returns although, as explained above, in the long run it can be expected to affect the rates of return on equity and bonds one-for-one. Nevertheless, the effect in the short run remains unclear, and is the reason we allow for the short-run effects of inflation in our econometric model. Thus, unlike Eq. (1), Eq. (2) also allows for a time-varying conditional mean and is therefore a VAR(1) in the conditional mean with disturbances that are normally distributed with mean zero and a timevarying variance-covariance matrix that is generated by an $\mathrm{M}-\mathrm{GARCH}(1,1)$ process.

The right-hand side of Eq. (2) can be interpreted as the implied measure of (or proxy for) the risk premia. Optimum portfolio allocation, with its focus on the conditional covariance matrix, can therefore be interpreted as being based on the risk-neutral distribution.

\subsection{Method of estimation}

Our model as specified in Eqs. (2) and (3) was estimated by maximising the log likelihood function

$$
\log L=-\frac{n T}{2} \log (2 \pi)-\frac{1}{2} \sum_{t}\left(\log \left|\Omega_{t}\right|-\boldsymbol{\xi}_{t+1}^{\prime} \Omega_{t}^{-1} \boldsymbol{\xi}_{t+1}\right)
$$

recursively using the Berndt, Hall, Hall, and Hausmann (1974, BHHH) algorithm. $n$ is the size of $\mathbf{z}$ and $T$ is the number of observations.

\section{Data issues}

\subsection{Choice of macroeconomic variables}

In principle, many macroeconomic variables could be included in our analysis. We restrict our analysis to one variable, inflation, for several reasons. Partly, it is due to the 
dimensionality problem and because this paper is designed to illustrate the methodology. Firstly, the choice of inflation is because, as noted above, if investors seek real returns then they will want to be fully compensated for inflation. It has also been argued by Schwert (1989) that if the inflation of goods' prices is uncertain, then the volatility of nominal asset returns should reflect inflation volatility. Second, the empirical evidence reviewed above is supportive of a strong relation between inflation and stock and bond returns. Third, empirical evidence on the relation between inflation and stock returns has produced something of a puzzle that has attracted much attention. Theory suggests that the relation between nominal asset returns and inflation would be positive but the empirical evidence usually finds the relation between stock returns and inflation is consistently negative across countries and over different time periods - see Bodie (1976) and Fama and Schwert (1977) for the United States and Gultekin (1983) and Solnik(1983) for a number of other countries. ${ }^{4}$

In choosing a suitable inflation variable, we were faced with the choice of a realised variable or an expectations variable. While both have been shown to have predictive power over U.S. stock returns, most research on UK stock returns has focussed on inflation measures based on the Retail Price Index (see Asprem, 1989; Clare \& Thomas, 1994). This measure is mostly likely to be priced into UK stock returns as this rate is most often used as the headline rate by UK market participants. Consequently, we use a realised variable in the results reported below. ${ }^{5}$

\subsection{Data}

We include three risky UK financial assets. These are equities, a long government bond, and a short government bond. Equity is represented by the Financial Times All Share Index, long government bonds are represented by the FT British government stock with over 15 years to maturity index, and short government bonds are represented by the FT British government stock with under 5 years to maturity index. Each is expressed as an excess return over the risk-free rate as proxied by the 30-day Treasury bill rate. The data used are monthly total annualised returns. ${ }^{6}$ The inflation rate is calculated from the UK Retail Price Index. As econometric tests fail to reject the null hypothesis of a unit root in inflation, the change in inflation is used to ensure that all variables are stationary. ${ }^{7}$ The data are from January 1976 to September 1996 and were sourced from DATASTREAM.

\footnotetext{
${ }^{4}$ Possible explanations of the puzzle have been offered by Nelson (1976), Geske and Roll (1983), and Groenewold et al. (1997).

${ }^{5}$ Using a WPI-based inflation measure yielded parameters of the same sign and similar magnitude but many had reduced statistical significance.

${ }^{6}$ Given that we use excess returns, we were faced with the question of annualising stock returns or "deannualising" the risk-free rate. In trying to achieve convergence in the M-GARCH model, it is better to work with annualised data rather than the smaller numbers associated with monthly returns. This is also the approach of Cumby et al. (1994).

${ }^{7}$ Unit root tests were conducted on all variables and results are available from the authors.
} 


\section{Results}

\subsection{Conditional mean}

Our estimates are reported in Appendix A. The estimates of the conditional mean broadly confirm that excess returns are unpredictable using this information set. The only significant coefficient in the $\beta$ matrix is in the inflation equation, and it is for the lagged change of inflation. In the intercept vector, $\alpha$ the only significant coefficient is for equity. This is consistent with having a substantial equity premium. The intercept for the excess returns on long bonds is quite large, but is not well determined.

When selecting financial asset portfolios, we use a vector of historical means as our proxy for expected returns. This approach has been advocated by Jobson and Korkie (1981) who demonstrate that this greatly improves portfolio performance. It is also argued in Flavin and Wickens (1998) that this approach is preferable given the insignificance of the estimated parameters in the mean equation already mentioned. As well as being expensive in terms of transaction costs, rebalancing our portfolio in response to changes in the predicted excess return would also be counterproductive due to the lack of persistence of the deviations of excess returns from their unconditional means. This is not true of rebalancing due to changes in the conditional variance because of their much higher degree of persistence and lower volatility.

\subsection{Conditional covariance matrix}

These estimates indicate that the covariance matrix is time varying. They also show that inflation plays a much more important role than in the conditional mean both in the long run and in the short run. In the long run, all excess returns are correlated with each other and with inflation. The implied long-run covariance matrix is obtained from $\mathbf{H}=\mathbf{V}^{\prime} \mathbf{V}$ and is

$$
H=\left[\begin{array}{ccccc}
3382.44 & & & \\
1417.91 & 1810.78 & & \\
524.21 & 515.14 & 228.43 & \\
-6.03 & -3.69 & -1.61 & 0.30
\end{array}\right]
$$

The lack of significance of $\mathbf{V}_{42}$ and $\mathbf{V}_{43}$ implies that the coefficient $\mathbf{V}_{41}$ plays a crucial role in the transmission mechanism of inflation volatility to the excess returns. Inflation volatility affects equity in the first instance and this is then transmitted to long and short bonds through the correlation between equity and bonds.

The negative sign on the covariances between the financial assets and the change in inflation is consistent with the findings of Groenewold, O'Rourke, and Thomas (1997). They conclude that inflation impacts the financial sector indirectly through its effect on other macro factors. 
Conditional Volatility of UK Equities

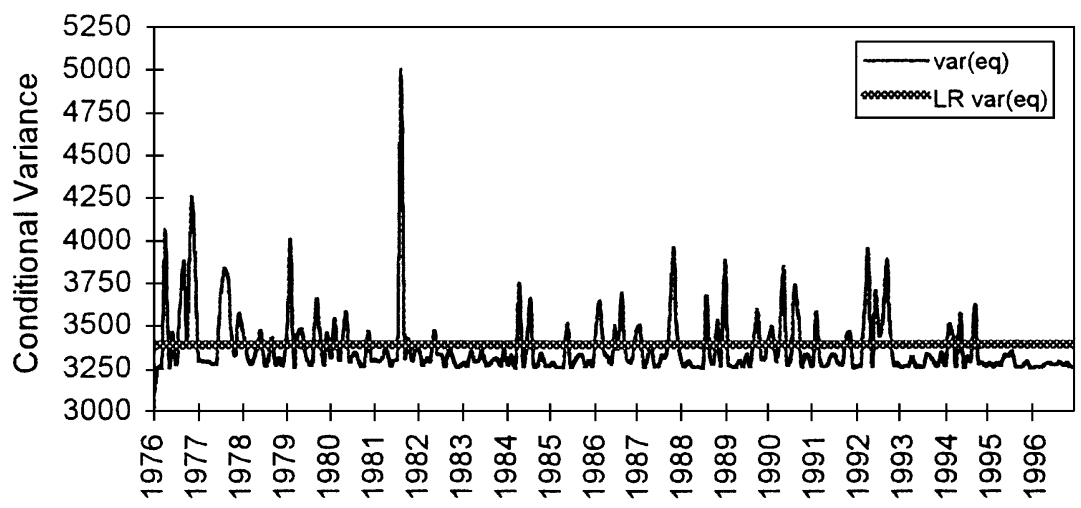

Conditional Volatility of UK Govt Long Bond

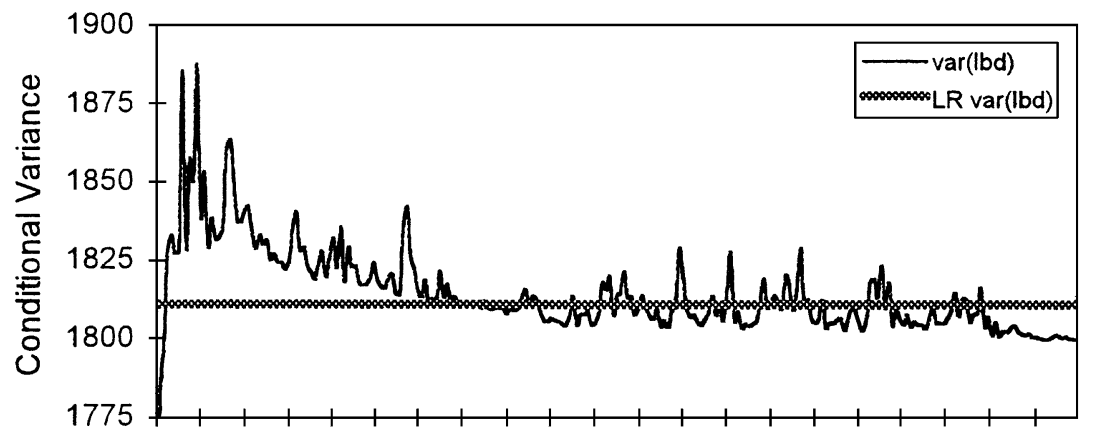

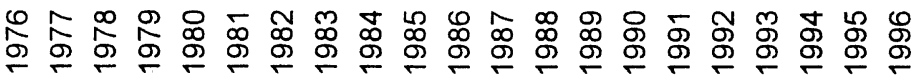

Conditional Volatility of UK Govt Short Bond

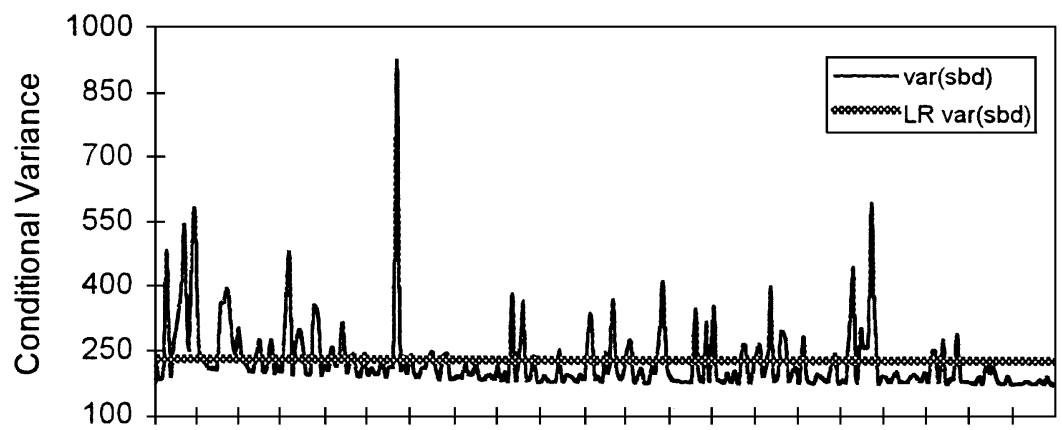

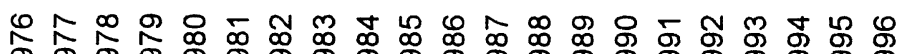

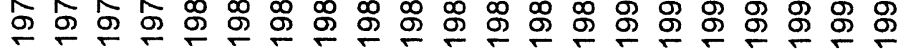

Fig. 1. Conditional asset variances. 
This differs from our results, which suggest inflation affects bonds via equities. Negative covariances between inflation and the asset returns suggest that in the long run higher inflation volatility tends to be associated with lower asset return volatilities.

The large number of significant estimates in the $\mathbf{A}$ and $\mathbf{B}$ matrices imply that the short run conditional covariance matrix differs from its long-run level. Roughly speaking, and ignoring the other elements, the greater the elements on the leading diagonals of $\mathbf{A}$ and $\mathbf{B}$, the more the conditional covariance matrix deviates from the long-run value. The off-diagonal elements contribute to the contagion effects in the short run. These estimates suggest that the deviations from the long-run covariance matrix are both persistent and predictable.

Fig. 1 depicts the long-run variances and the short-run conditional variances of the three excess asset returns. The short-run deviations are clearly substantial. The conditional variances are usually below their long-run value (especially for equity and the short bond). This suggests that for much of the time, investors can hold more equity and short-run bonds than use of the long-run covariance matrix would imply.

The impact of inflation volatility on short-run asset return volatility is very important, especially for the long bond, as both $\mathbf{B}_{42}$ and $\mathbf{A}_{42}$ are statistically significant. Inflation volatility also affects the short-run volatility of UK equity as $\mathbf{B}_{41}$ and $\mathbf{A}_{41}$ are marginally significant. The short bond seems to be least affected although there is evidence of significance in the $\mathbf{A}_{43}$ parameter.

Viewed as a whole, these results show that while asset returns are close to being unpredictable, asset return volatility is time-varying, persistent, and much more predictable. They offer considerable support for taking account of inflation in explaining the volatility of asset returns, and the preliminary indication is that the optimum portfolio allocation may involve holding more equity than the portfolio allocation based on a constant volatility would suggest. We now examine the implications for asset allocation in more detail.

\section{Portfolio selection}

\subsection{The portfolio frontier}

As explained earlier, to form optimal portfolios, we require the conditional covariance matrix of the joint marginal distribution of the excess asset returns. To obtain this, we simply partition conformably with the subvector of asset returns. Next, we generate the time-varying minimum variance portfolio (MVP) frontiers using historical returns as a proxy for expected returns. The time variation in the conditional covariance matrix of returns is reflected in the time variation in the frontiers, and implies that portfolios will need to be continuously rebalanced to be optimal.

Fig. 2 shows the distribution of frontiers generated over the entire 20-year sample. The range of movement is quite large and the shape changes too. For the MVPs, the minimum standard deviation of the portfolio is about $6 \%$ and the maximum is roughly $22 \%$.

It is instructive to compare these frontiers with those obtained by Flavin and Wickens (1998), which take no account of the macroeconomic factor. These are displayed in Fig. 3. In 


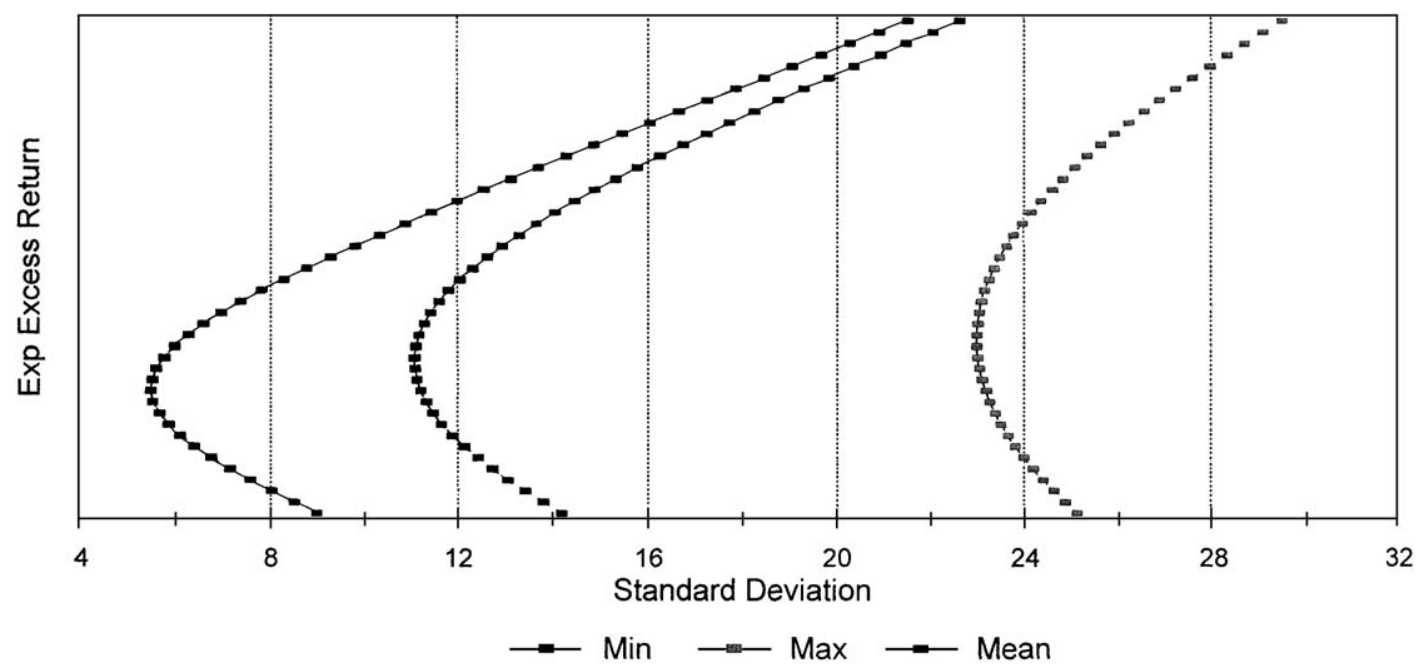

Fig. 2. Distribution of portfolio frontiers.

general, taking account of inflation results in the whole distribution of mean variance frontiers shifting to the left, and a more negatively skewed distribution as while the mean is little changed, the minimum and the maximum frontiers are shifted to the left. A possible

\section{Time-Varying Portfolio Frontiers}

Influence of Inflation

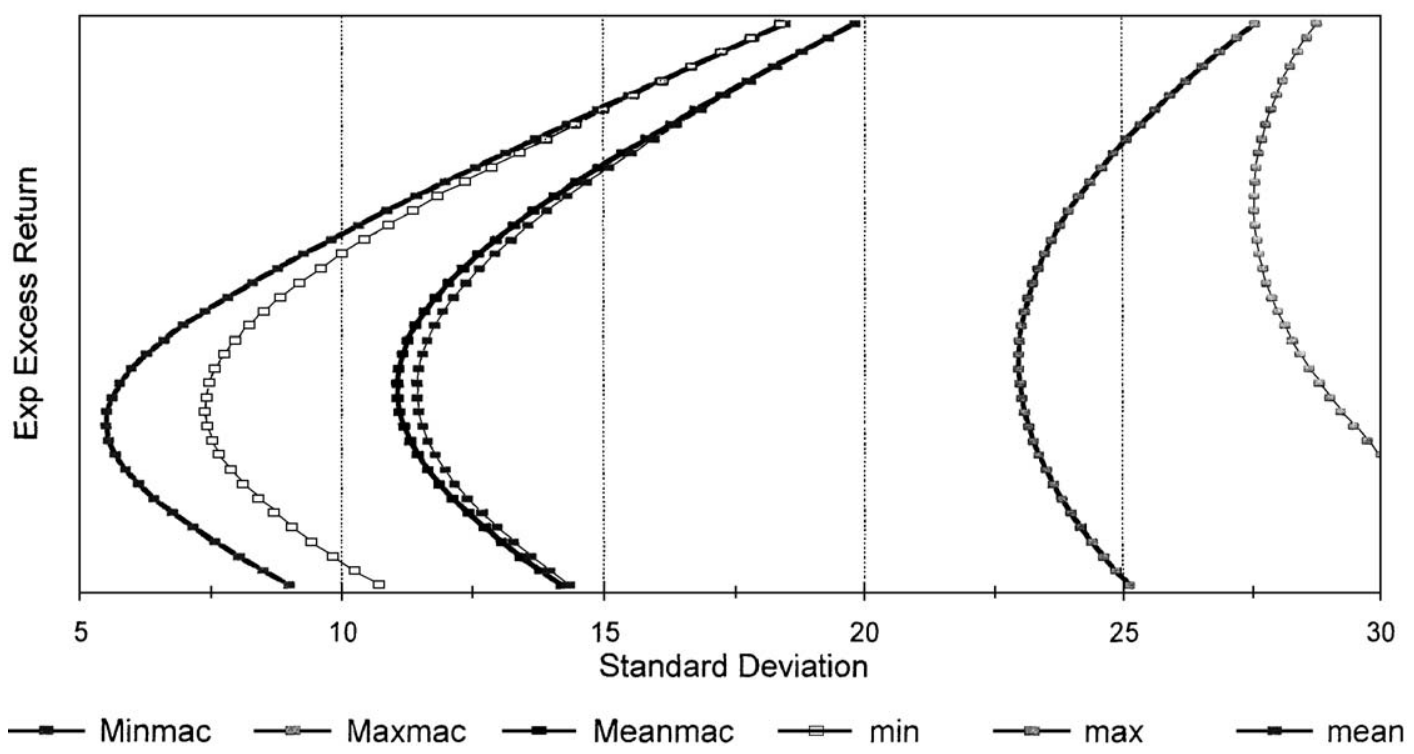

Fig. 3. Influence of inflation on distribution of portfolio frontiers. 
reason why the mean portfolio frontiers are similar is that by omitting inflation from the econometric model, in effect the bias introduced is evaluated at the mean level and long-run variance of inflation. This shift to the left in the frontier is due mainly to the negative conditional covariance between equity excess returns and inflation. It implies that investors can achieve a higher expected return for any given level of risk, or lower risk for any given level of return.

Fig. 4 tells a similar story. It depicts the mean frontiers obtained in a number of different ways. The left-most frontier is the optimal frontier based on taking full account of inflation. Moving to the right, the next frontier ignores inflation. The third and fourth frontiers are based on the respective long-run solutions of these two approaches. These use $\mathbf{V}^{\prime} \mathbf{V}$ instead of the conditional covariance matrices. The final two frontiers have been computed from a simple OLS estimate of the unconditional covariance matrix of excess returns. These results show the benefits of taking account of inflation and of using an estimate of the conditional covariance matrix. They also show that even if the constant long-run covariance matrix is used, it is better to estimate this from the short-term model.

\subsection{Portfolio selection}

We consider three types of portfolio, the MVP, the optimal unconstrained portfolio (OUP), and the optimal constrained portfolio (OCP). All three take account of the influence of inflation and are based on holding only risky assets. The two latter portfolios represent the

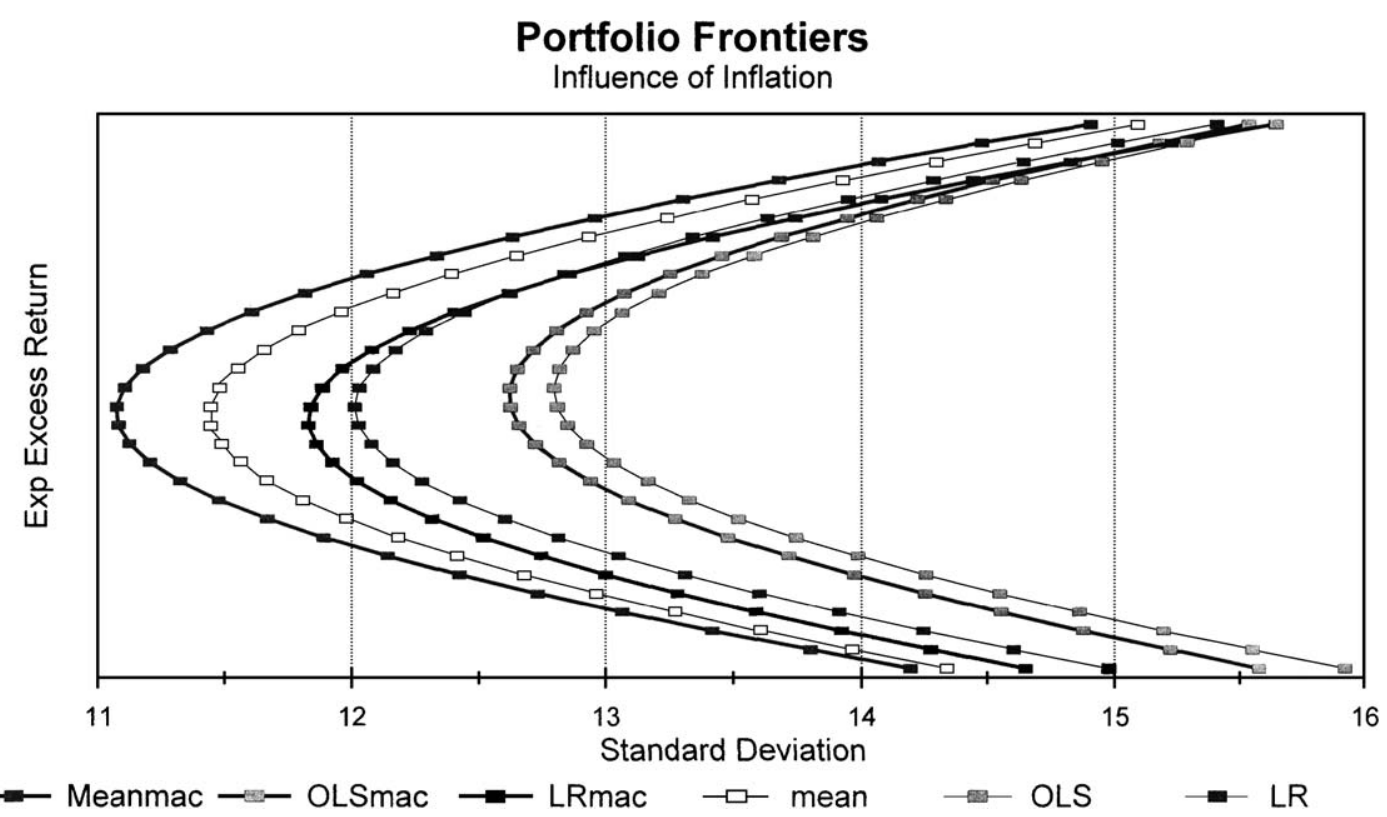

Fig. 4. Influence of inflation on conditional versus unconditional portfolio frontiers. 
Excess Return on Optimal Portfolio of Risky Assets

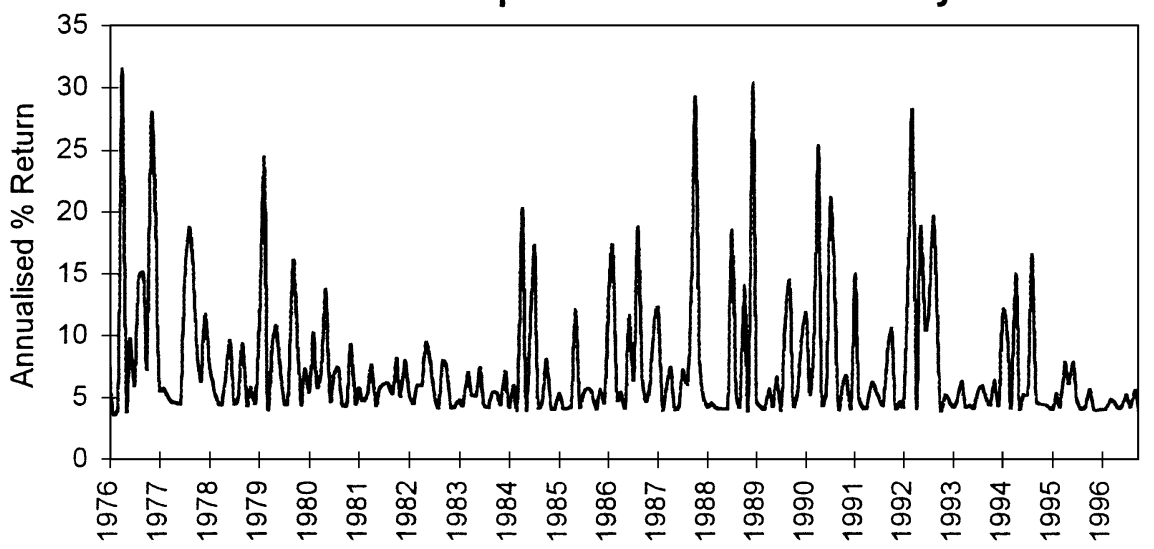

Standard Deviation of Optimal Portfolio of Risky Assets

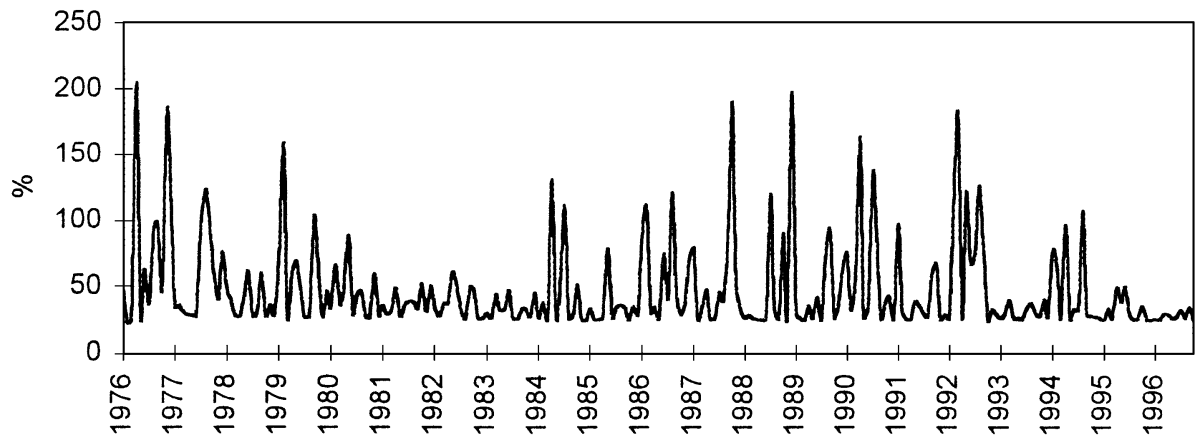

Fig. 5. Risk-return features of minimum variance and optimal portfolios.

optimal portfolio of risky assets and based on CAPM would be held together with a risk-free asset. However, we identify the constituents of the risky portfolio and leave the final investment position to the individual. The OUP allows the portfolio weights to be negative, and hence permits short sales, and the OCP is restricted to have nonnegative weights. The location of the OUP can be represented as a point on the tangent from the portfolio frontier to the risk-free rate of interest. The OCP not only restricts the asset shares to be nonnegative, it

Table 1

Summary statistics for minimum variance and optimal portfolios

\begin{tabular}{llllllll}
\hline & Return & & & & \multicolumn{3}{l}{ Standard deviation } \\
\cline { 2 - 3 } & Mean & Maximum & Minimum & & Mean & Maximum & Minimum \\
\hline MVP & 0.45 & 1.21 & 0.21 & & 11.02 & 22.97 & 5.50 \\
Optimal & 7.55 & 31.54 & 3.62 & & 47.75 & 204.22 & 22.27 \\
\hline
\end{tabular}




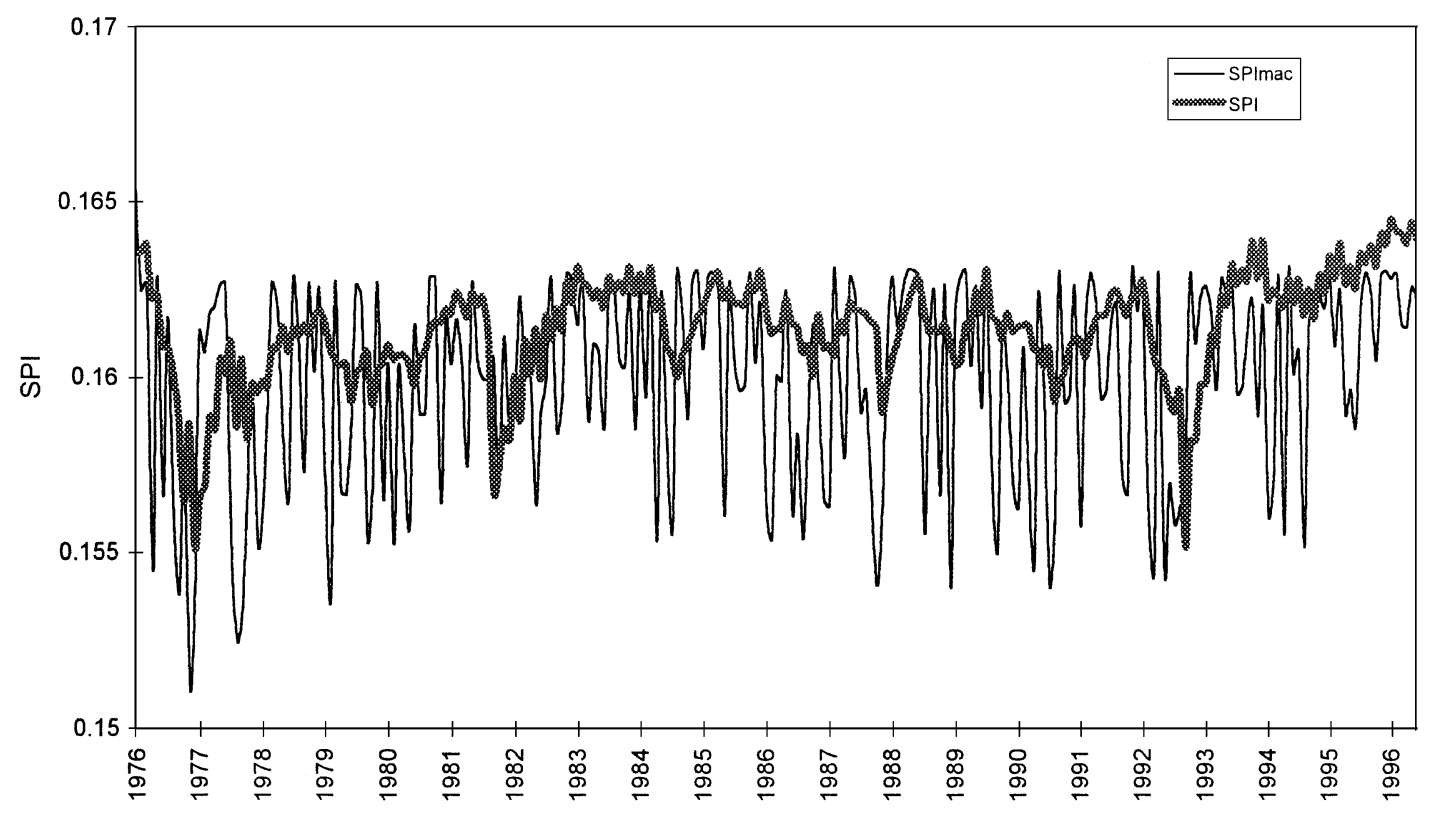

Fig. 6. Sharpe performance indices for optimal portfolios.

is also constrained to have the average return on the unrestricted portfolio. In this way, investors are not penalised by the restriction on the shares and it aids comparisons with the unrestricted case. The OCP requires the use of quadratic programming.

\subsubsection{Unrestricted weights}

Fig. 5 plots the excess return and standard deviation of the MVP and the OUP. While the return on the OUP is always higher than that of the MVP, so is the standard deviation. Table 1 provides a summary of the key features of these portfolios.

A common measure of overall portfolio performance is the Sharpe Performance Index, which is defined as SPI=(excess rtn)/risk. In Fig. 6, we report the SPI for the OUP both with and without taking account of inflation. We only compute the SPI for the OUP as this is higher than those for the MVP. The two portfolios have similar SPI values. This is consistent with the convergence of the frontiers in the efficient region. The mean values are about 0.16 .

Table 2

Allocation based on long-run conditional covariance matrix

\begin{tabular}{lccc}
\hline & Equity $(\%)$ & Long bond $(\%)$ & Short bond $(\%)$ \\
\hline MVP & -6 & -25 & 131 \\
Optimal & 80 & 19.7 & 0.3 \\
\hline
\end{tabular}




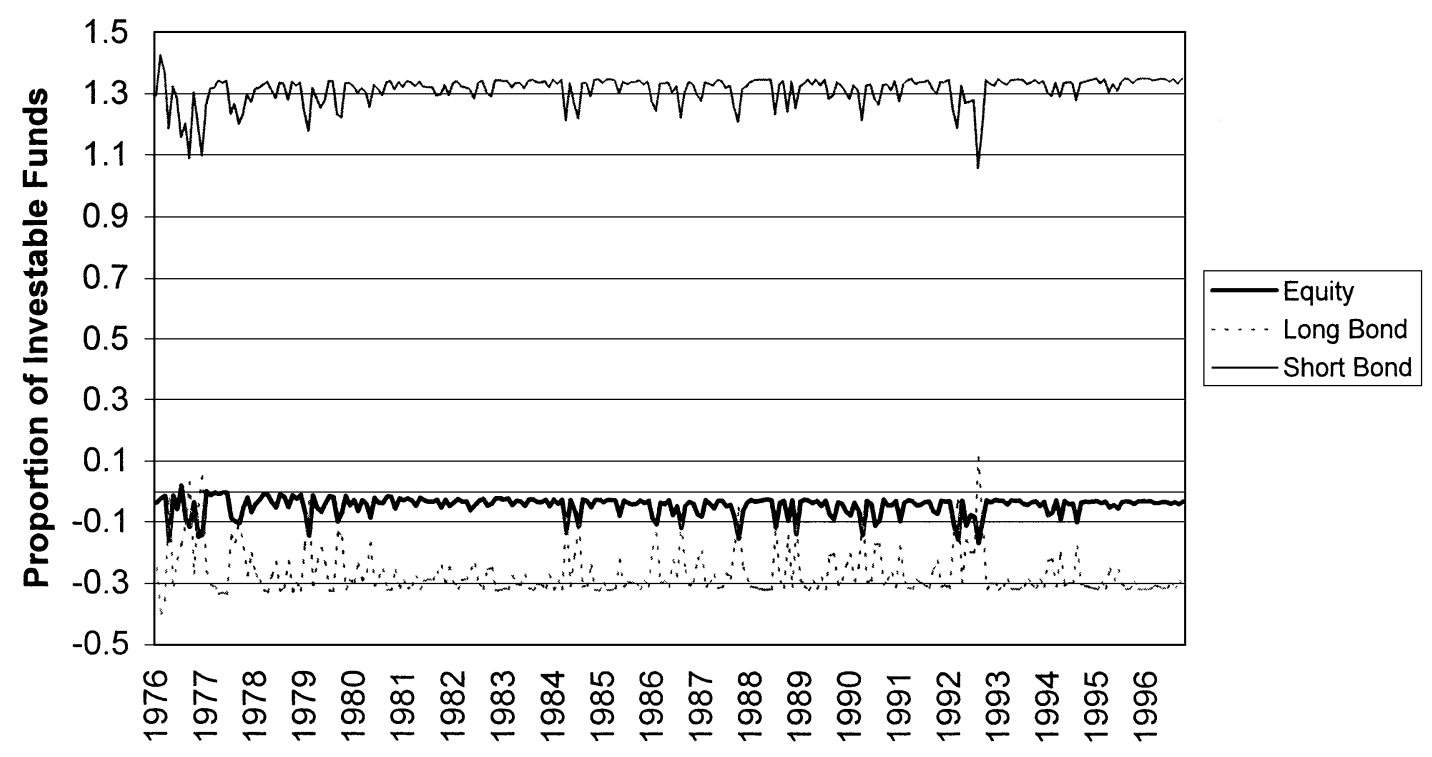

Fig. 7. Unrestricted minimum variance portfolio asset holdings.

The average asset shares for the MVP and the OUP are reported in Table $2{ }^{8}$ They are strikingly different. Whereas the MVP is dominated by the short bond and equity is sold short, the OUP is dominated by equity and the share in the short bond is miniscule. Figs. 7 and 8 plot the shares for the two portfolios and Table 3 presents summary statistics. For the MVP, the shares are very stable across time. The short bond always accounts for more than $100 \%$ of wealth and is funded mainly by a short position in the long bond, though equity is also predominantly held short. The inclusion of the inflation innovation has not greatly altered the share of asset holdings, but it has dampened the volatility in bond holdings.

In the OUP, equity dominates, on average accounting for $73 \%$ of the portfolio. It is never held short and its share is often in excess of $100 \%$ of wealth. One or both of the bonds are then held short to make this investment possible. Comparing the OUP shares with those found by Flavin and Wickens (1998), which do not take account of inflation, the holdings of bonds are more volatile, the mean holding of the long bond is reduced from $20 \%$ to $16 \%$ (see Table 3) and the investor holds bonds short on many more occasions. The short government bond is still the most volatile asset, ranging from $-425 \%$ to $83 \%$ of investor wealth, but its mean holding has remained largely unaltered with only a slight increase from $10 \%$ to $11 \%$. This would seem to be due to the smaller influence of inflation on the volatility of the short

\footnotetext{
${ }^{8}$ These weight vectors are computed using standard results for portfolio mathematics (see Huang \& Litzenberger, 1988).
} 


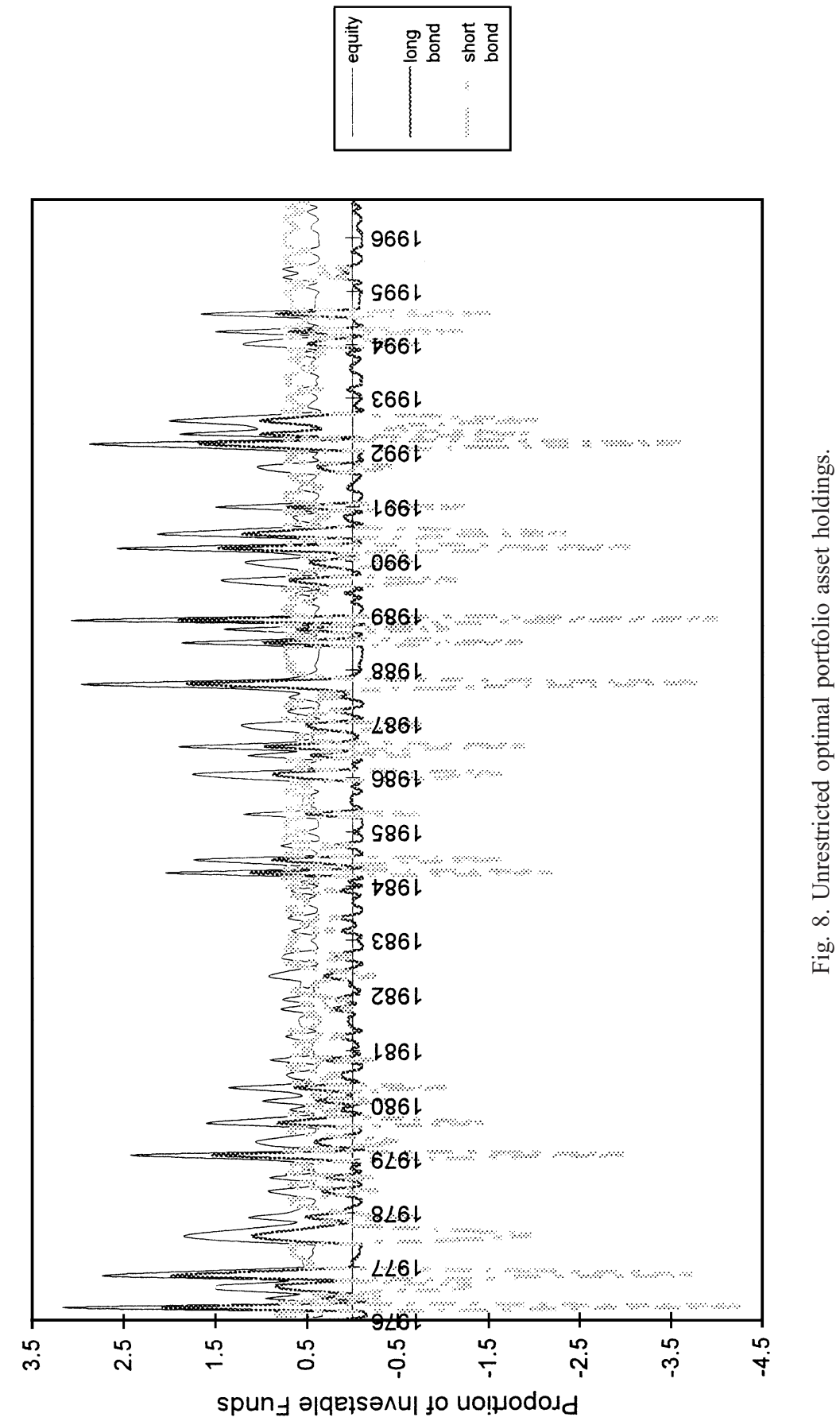


Table 3

Key features of the unrestricted allocations

\begin{tabular}{|c|c|c|c|c|c|c|}
\hline & \multicolumn{3}{|c|}{ Including inflation effect } & \multicolumn{3}{|c|}{ Excluding inflation effect ${ }^{\mathrm{a}}$} \\
\hline & Mean & Maximum & Minimum & Mean & Maximum & Minimum \\
\hline \multicolumn{7}{|l|}{$M V P$} \\
\hline Equity & -5 & 2 & -17 & -4 & 1 & -12 \\
\hline Long bond & -25 & 11 & -40 & -27 & 32 & -40 \\
\hline Short bond & 130 & 143 & 106 & 131 & 139 & 75 \\
\hline \multicolumn{7}{|l|}{ Optimal } \\
\hline Equity & 73 & 317 & 33 & 70 & 160 & 38 \\
\hline Long bond & 16 & 207 & -16 & 20 & 84 & -4 \\
\hline Short bond & 11 & 83 & -425 & 10 & 65 & -145 \\
\hline
\end{tabular}

${ }^{a}$ Results are taken from Flavin and Wickens (1998).

government bond as inflation may be more predictable at shorter horizons and hence not as great a source of uncertainty as the short asset.

\subsubsection{Restricted weights}

The OCP removes some of the undesirable features of the OUP, in particular the volatility of asset shares. It also eliminates short sales. Fig. 9 shows that equity dominates the OCP in

Asset Holdings in Risky Portfolio

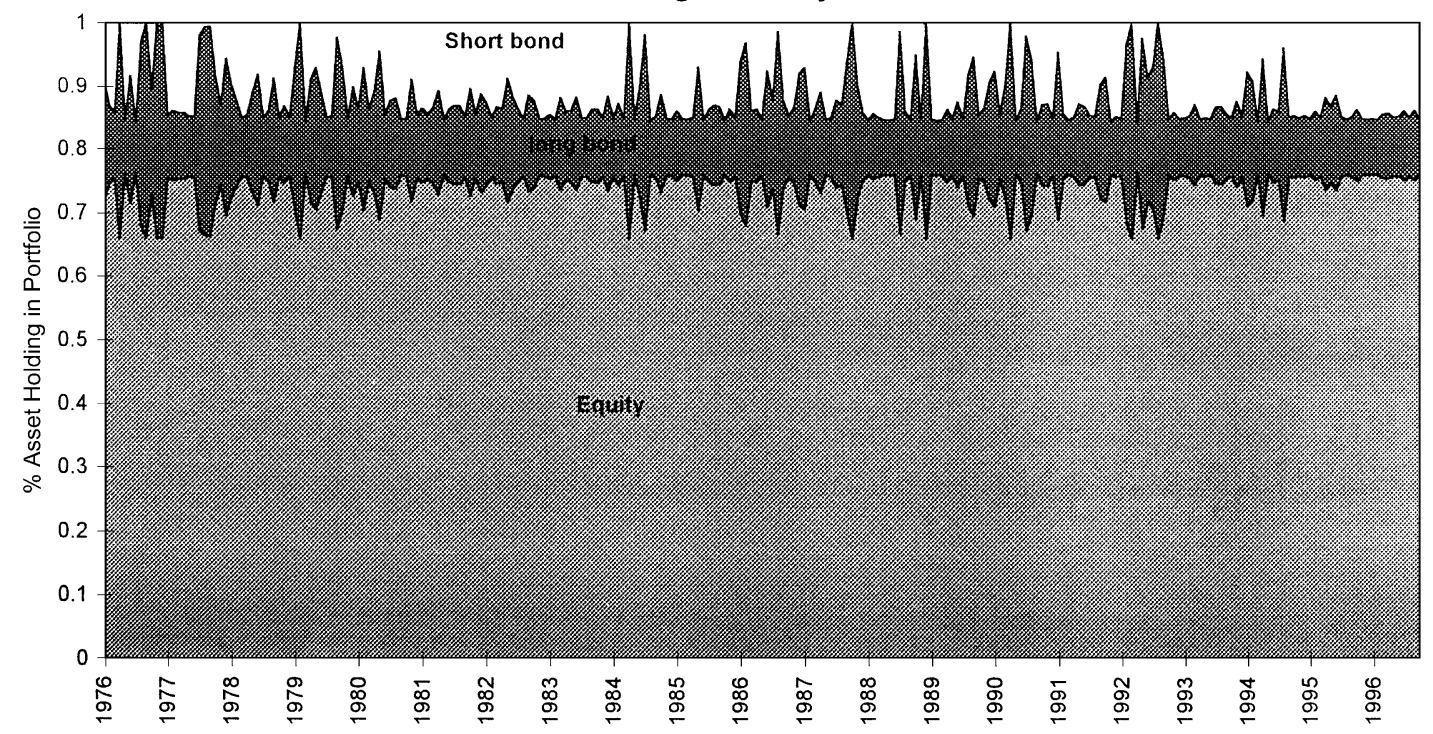

Fig. 9. Restricted portfolio asset holdings. 
Table 4

Key features of the restricted allocation

\begin{tabular}{llll}
\hline & Mean (\%) & Minimum (\%) & Maximum \\
\hline Equity & 74 & 66 & 76 \\
Long bond & 14 & 8 & 34 \\
Short bond & 12 & 0 & 16 \\
\hline
\end{tabular}

every period, and the share is quite stable around the average position of $74 \%$ of the portfolio. The long bond continues to dominate the short bond, but this is not as pronounced as in the unrestricted allocation. The mean holdings of the long and short bonds are $14 \%$ and $12 \%$ of the portfolio, respectively. Table 4 summarises the asset holdings under this investment strategy.

Table 5 compares these OCP shares with those of Flavin and Wickens (1998) that do not take account of inflation. There is an increase in the share of both equity (from $70 \%$ to $74 \%$ ) and the short-term bond (from $10 \%$ to $12 \%$ ). These increases are offset by a reduction in the holding of the long bond (from $20 \%$ to $14 \%$ ). The increase in equity again reflects the negative correlation of excess equity returns with inflation.

\subsection{Portfolio performance}

To further help determine whether the effort involved in taking of account of inflation has improved portfolio performance, we compare the OCP with a portfolio with constant asset shares equal to the average weights for the OUP reported in Table 2. In Fig. 10, we plot the ratios of the expected return and the standard deviation on the OCP to the constant proportions OUP. The main difference lies in the riskiness of the portfolios. In every period, the risk associated with the OCP is much lower-on average by almost $24 \%$. The OCP has a lower average return, but the ratio is close to unity most of the time.

We also compare the realised return and the realised volatility of returns from the OCP with those from the constant shares portfolio. We find that the OCP has a slightly lower return - as above - but is compensated by a lower realised volatility. This is evidenced by an increase of $1.6 \%$ in the Sharpe Performance Index.

Table 5

Effect of inflation innovations on mean asset holdings

\begin{tabular}{lllr}
\hline & Including inflation effect (\%) & Excluding inflation effect & Change \\
\hline Equity & 70 & 74 & +4 \\
Long bond & 20 & 14 & -6 \\
Short bond & 10 & 12 & +2 \\
\hline
\end{tabular}




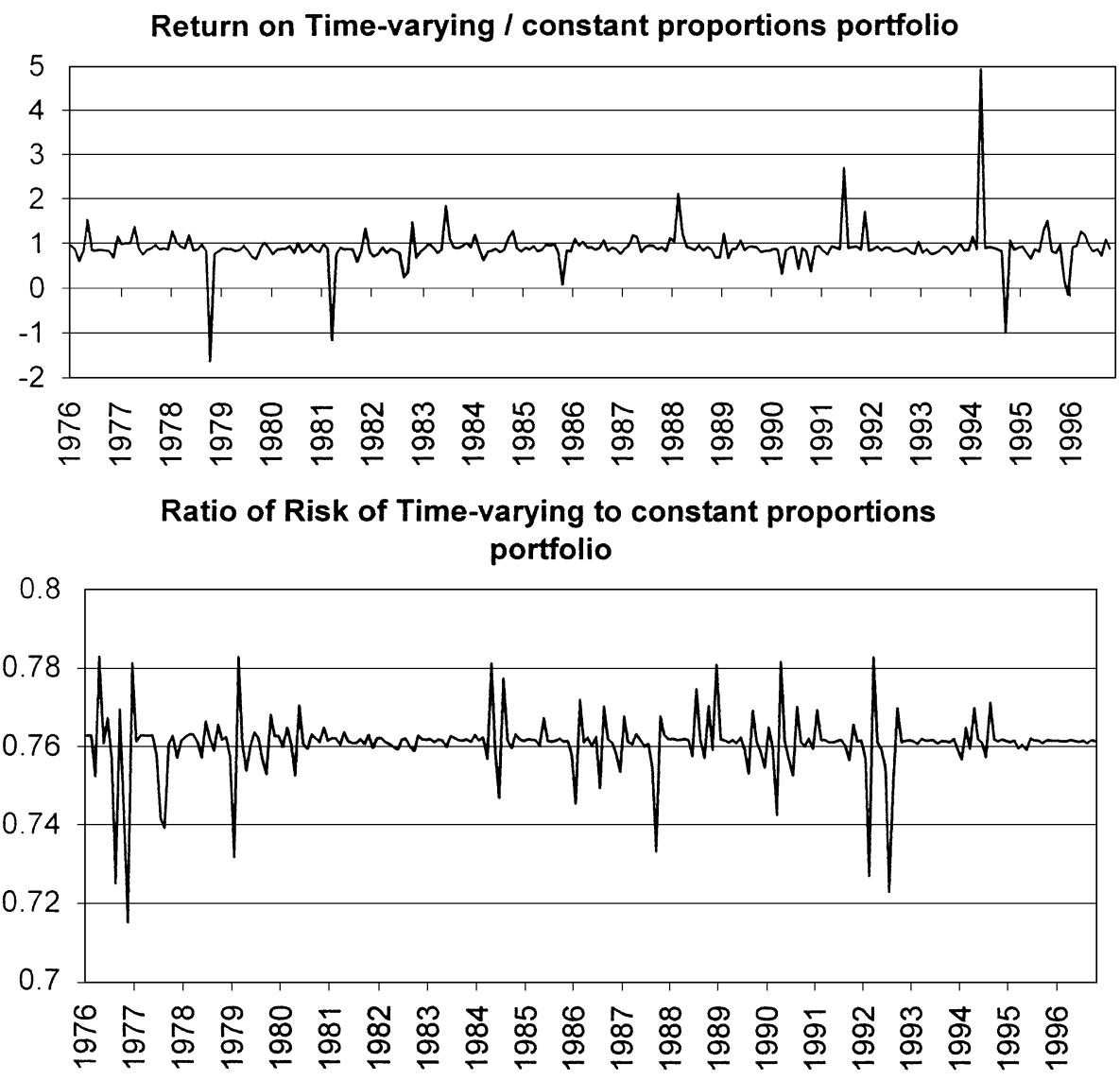

Fig. 10. Risk-return benefits of time-varying portfolio.

We conclude, therefore, that the greatest benefit of this approach to asset allocation lies in its potential to reduce portfolio risk. This finding should further encourage fund managers to adopt this asset allocation strategy.

\section{Conclusion}

In this paper, we have described a way to take account of macroeconomic factors in tactical asset allocation. The methodology is based on an extension of standard CAPM in which the MVP frontier is allowed to vary over time and to reflect variations in macroeconomic factors. Flavin and Wickens (1998) show that a tactical asset allocation strategy that involves continuously rebalancing a portfolio in response to changes in the conditional covariance matrix permits a large reduction in risk over and above a portfolio based upon a constant covariance matrix. We have shown here that extending this analysis to allow for the 
incorporation of macroeconomic variables in determining the covariance matrix of returns allows further significant gains in risk reduction.

Our analysis, which is illustrative of the methodology, involves four financial returns (three risky assets and a risk-free asset), one macroeconomic variable (inflation), and is for the UK. The risky assets are UK equity, a long-term UK government bond, and a short-term UK government bond. The risk-free asset is the 30-day Treasury bill.

A crucial feature of the analysis is the ability to estimate the joint distribution of the excess returns and the macroeconomic factors to allow for a time-varying covariance structure to the distribution. This permits the macroeconomic factors to continuously influence the covariance matrix of asset returns and hence the portfolio frontier formed from the covariance matrix of the marginal joint distribution of returns. We employed a multivariate $\operatorname{GARCH}(1,1)$ model, but other models could be used.

We have found that inflation has a significant impact on the conditional covariance matrix of asset returns. The transmission mechanism seems to be via its effect on the volatility of equity. Inflation is negatively correlated with all three excess returns in the long run, but the long-run impact is greatest on equity; the impact on bonds is predominantly a short-run phenomenon. The negative covariance between inflation and the excess returns generates a significant reduction in portfolio risk over and above what can be achieved by using a timevarying covariance matrix of excess returns alone. The risk of the time-varying portfolio is at least $20 \%$ lower than that of the constant proportions portfolio. There is also an improvement in overall portfolio performance as measured by the SPI with the reduction in portfolio volatility more than offsetting a lower realised average return. The unconstrained portfolio has highly volatile shares, but the constrained portfolio is reasonably stable. The average OCP shares are: equity $74 \%$, the long bond $14 \%$, and the short bond $12 \%$.

\section{Acknowledgements}

The authors gratefully acknowledge the constructive comments offered by two anonymous referees.

\section{Appendix A. The estimates}

Model:

$$
\begin{aligned}
& \mathbf{z}_{t}=\boldsymbol{\alpha}+\boldsymbol{\beta} z_{t-1}+\boldsymbol{\gamma d u m} 87+\boldsymbol{\zeta}_{t} \\
& \boldsymbol{\xi}_{t} \mid \Psi,_{t-1} \sim N\left(0, \mathbf{H}_{t}\right) \\
& \mathbf{H}_{t}=\mathbf{V}^{\prime} \mathbf{V}+\mathbf{A}^{\prime}\left(\mathbf{H}_{t-1}-\mathbf{V}^{\prime} \mathbf{V}\right) \mathbf{A}+\mathbf{B}^{\prime}\left(\boldsymbol{\xi}_{t-1} \boldsymbol{\xi}_{t-1}^{\prime}-\mathbf{V}^{\prime} \mathbf{V}\right) \mathbf{B} \\
& z=(\text { ukeg, lbd, sbd, } \Delta \pi)^{\prime}
\end{aligned}
$$

$t$ statistics are reported in parentheses. 
As $\mathbf{V}, \mathbf{A}$, and $\mathbf{B}$ are symmetric, we report only the lower triangle.

Conditional mean:

$$
\boldsymbol{\alpha}=\left[\begin{array}{c}
11.93 \\
(3.35) \\
4.76 \\
(1.56) \\
0.94 \\
(0.97) \\
-0.032 \\
(-0.83)
\end{array}\right], \boldsymbol{\beta}=\left[\begin{array}{cccc}
-0.04 & 0.24 & -0.33 & -5.13 \\
(-0.65) & (1.77) & (-0.92) & (-0.98) \\
0.03 & 0.02 & 0.14 & -4.27 \\
(0.52) & (0.19) & (0.56) & (-0.98) \\
-0.04 & 0.06 & 0.04 & -0.01 \\
(-1.67) & (1.55) & (0.54) & (0.1) \\
0.001 & -0.001 & 0.004 & 0.40 \\
(0.72) & (-0.44) & (-0.59) & (4.62)
\end{array}\right], \boldsymbol{\gamma}=\left[\begin{array}{c}
-420.98 \\
(-1.43) \\
0 \\
0 \\
\end{array}\right]
$$

Conditional covariance:

$$
\begin{aligned}
& \mathbf{V}=\left[\begin{array}{cccc}
58.16 & & & \\
(24.10) & & & \\
24.38 & 34.88 & & \\
(10.22) & (34.29) & \\
9.01 & 8.47 & 8.69 & \\
(10.35) & (13.31) & (15.27) & \\
-0.104 & -0.033 & -0.046 & 0.536 \\
(-1.83) & (-0.56) & (-0.48) & (5.11)
\end{array}\right], \quad \mathbf{B}=\left[\begin{array}{ccccc}
0.17 & & & \\
(3.78) & & & \\
0.02 & 0.015 & & \\
(0.59) & (0.45) & & \\
0.087 & -0.013 & 0.21 & \\
(5.25) & (-0.41) & (2.32) & \\
-0.003 & 0.006 & 0.004 & -0.19 \\
(-1.46) & (2.44) & (0.42) & (-1.44)
\end{array}\right], \\
& \mathbf{A}=\left[\begin{array}{cccc}
0.08 & & & \\
(0.25) & & & \\
-0.51 & -0.003 & & \\
(-3.72) & (-0.01) & & \\
-0.17 & 0.58 & 0.27 & \\
(-0.86) & (4.06) & (0.92) & \\
0.06 & -0.15 & -0.08 & -0.48 \\
(1.39) & (-3.73) & (-1.43) & (-1.51)
\end{array}\right]
\end{aligned}
$$




\section{References}

Ait-Sahalia, Y., \& Brandt, M. W. (2001). Variable selection for portfolio choice. Journal of Finance, 56, 1297-1351. Asprem, M. (1989). Stock prices, asset portfolios and macroeconomic variables in ten European countries. Journal of Banking and Finance, 13, 589-612.

Baba, Y., Engle, R. F., Kraft, D. F., \& Kroner, K. F. (1990). Multivariate simultaneous generalized ARCH [mimeo]. Department of Economics, University of California at San Diego.

Bera, A. K., \& Higgins, M. L. (1993). ARCH models: properties, estimation and testing. Journal of Economic Surveys, 7, 305-366.

Berndt, E. R., Hall, B. H., Hall, R. E., \& Haussman, J. A. (1974). Estimation and inference in nonlinear structural models. Annals of Economic and Social Management, 4, 653-665.

Bodie, Z. (1976). Common stocks as a hedge against inflation. Journal of Finance, 31, 459-470.

Bollerslev, T., Engle, R. F., \& Nelson, D. B. (1994). ARCH models. In R. F. Engle, \& D. L. McFadden (Eds.), Handbook of econometrics. North-Holland: Elsevier.

Campbell, J. Y. (1987). Stock returns and the term structure. Journal of Financial Economics, 18, 373-399.

Campbell, J. Y., \& Ammer, J. (1993). What moves the stock and bond markets? A variance decomposition for long-term asset returns. Journal of Finance, 48, 3-37.

Campbell, J. Y., \& Shiller, R. J. (1988). The dividend-price ratio and expectations of future dividends and discount factors. Review of Financial Studies, 1, 195-228.

Campbell, J. Y., \& Shiller, R. J. (1991). Yield spreads and interest rate movements: a bird's eye view. Review of Economic Studies, 58, 495-514.

Chen, N., Roll, R., \& Ross, S. A. (1986). Economic forces and the stock market. Journal of Business, 59, 383-406.

Clare, A. D., O'Brien, R., Thomas, S. H., \& Wickens, M. R. (1998). Macroeconomic shocks and the domestic CAPM: evidence from the UK stock market. International Journal of Finance and Economics, 3, 111-126.

Clare, A. D., Smith, P. N., \& Thomas, S. H. (1997). Predicting UK stock returns and robust tests of mean variance efficiency. Journal of Banking and Finance, 21, 641-660.

Clare, A. D., \& Thomas, S. H. (1994). Macroeconomic factors, the APT, and the UK stock market. Journal of Business Finance and Accounting, 309-330.

Clare, A. D., Thomas, S. H., \& Wickens, M. R. (1993). Is the gilt-equity yield ratio useful for predicting UK stock returns. Economic Journal, 104, 303-315.

Clarke, R. G., \& de Silva, H. (1998). State-dependent asset allocation. Journal of Portfolio Management, 24, 57-64.

Cumby, R. E., Figlewski, S., \& Hasbrouck, J. (1994). International asset allocation with time varying risk: an analysis and implementation. Japan and the World Economy, 6, 1-25.

Engel, C., \& Rodrigues, A. P. (1989). Tests of international CAPM with time-varying covariances. Journal of Applied Econometrics, 4, 119-138.

Engle, R. F., \& Kroner, K. F. (1995). Multivariate simultaneous generalized ARCH. Econometric Theory, 11, $122-150$.

Fama, E. F. (1984). The information in the term structure. Journal of Financial Economics, 13, 509-528.

Fama, E. F., \& French, K. F. (1989). Business conditions and expected returns on stocks and bonds. Journal of Financial Economics, 25, 23-49.

Fama, E. F., \& French, K. R. (1992). The cross-section of expected stock returns. Journal of Finance, 47, 427-465.

Fama, E. F., \& French, K. R. (1995). Size and book-to-market factors in earnings and returns. Journal of Finance, $50,131-155$.

Fama, E. F., \& Schwert, G. W. (1977). Asset returns and inflation. Journal of Financial Economics, 5, 115-146.

Ferson, W. E., \& Harvey, C. R. (1997). Fundamental determinants of international equity returns: a perspective on conditional asset pricing. Journal of Banking and Finance, 21, 1625-1665.

Flavin, T. J., \& Wickens, M. R. (1998). A risk management approach to optimal asset allocation. Working paper, N85/12/98, NUI Maynooth.

Geske, R., \& Roll, R. (1983). The fiscal and monetary linkage between stock returns and inflation. Journal of Finance, 38, 1-33. 
Groenewold, N., O'Rourke, G., \& Thomas, S. (1997). Stock returns and inflation: a macro analysis. Applied Financial Economics, 7, 127-136.

Gultekin, N. B. (1983). Stock market returns and inflation: evidence from other countries. Journal of Finance, 38, $49-65$.

Harvey, C. R. (1991). The world price of covariance risk. Journal of Finance, 46, 111-157.

Hodrick, R. J. (1992). Dividend yields and expected stock returns, alternative procedures for inference and measurement. Review of Financial Studies, 5, 357-386.

Huang, C. F., \& Litzenberger, R. H. (1988). Foundations for financial economics. Amsterdam: North-Holland.

Jankus, J. C. (1997). Relating global bond yields to macroeconomic forecasts. Journal of Portfolio Management, 23, 96-101.

Jobson, J. D., \& Korkie, B. (1981). Putting Markowitz theory to work. Journal of Portfolio, 70-74.

Keim, D. B., \& Stambaugh, R. F. (1986). Predicting returns in the stock and bond markets. Journal of Financial Economics, 17, 357-390.

Klemkosky, R. C., \& Bharati, R. (1995). Time-varying expected returns and asset allocation. Journal of Portfolio Management, 21, 80-87.

Lintner, J. (1965). The valuation of risk assets and the selection of risky investments in stock portfolios and capital budgets. Review of Economics and Statistics, 47, 13-37.

Markowitz, H. M. (1952). Portfolio selection. Journal of Finance, 7, 77-91.

Markowitz, H. M. (1959). Portfolio selection: efficient diversification of investments. New York: Wiley.

Nelson, C. R. (1976). Inflation and rates of return on common stock. Journal of Finance, 31, 471-483.

Patelis, A. D. (1997). Stock return predictability and the role of monetary policy. Journal of Finance, 52, $1951-1972$.

Pesaran, M. H., \& Timmermann, A. (1995). Predictability of stock returns: robustness and economic significance. Journal of Finance, 50, 1201-1228.

Rozeff, M. (1984). Dividend yields are equity risk premiums. Journal of Portfolio Management, 10, 68-75.

Schwert, G. W. (1989). Why does stock market volatility change over time? Journal of Finance, 44, 1115-1153.

Sharpe, W. F. (1964). Capital asset prices: a theory of market equilibrium under conditions of risk. Journal of Finance, 19, 425-442.

Solnik, B. (1983). The relation between stock prices and inflationary expectations: the international evidence. Journal of Finance, 39, 35-48.

Tzavalis, E., \& Wickens, M. R. (1997). Explaining the failures of term spread models of the rational expectations hypothesis of the term structure. Journal of Money Credit and Banking, 29, 364-380.

Wickens, M. R., \& Smith, P. N. (2001). Macroeconomic sources of FOREX risk. Discussion Paper No. 2001/13, University of York. 